\title{
Principais causas de perdas gestacionais na espécie equina: Revisão
}

\section{Larissa Marchiori Sena ${ }^{1 *}$, Nara Clara Lazaroni e Merchid ${ }^{2}$, Ítalo Câmara de Almeida ${ }^{3}$, Jacymara Dutra Santos ${ }^{4}$, Carla Braga Martins ${ }^{5}$}

\author{
'Mestranda em Ciências Veterinárias, Centro de Ciências Agrárias e Engenharias, Universidade Federal do Espírito Santo \\ - Alegre/ES-Brasil-Email: Imsmvet@gmail.com* \\ ${ }^{2}$ Mestranda em Ciências Veterinárias, Centro de Ciências Agrárias e Engenharias, Universidade Federal do Espírito Santo - \\ Alegre/ES-Brasil-Email: nara.merchid@ufv.br \\ ${ }^{3}$ Médico Veterinário, Ms, Auxiliar de Veterinária e Zootecnia-Centro de Ciências Agrárias e Engenharias- Universidade \\ Federal do Espírito Santo - Alegre/ES-Brasil-Email: almeidaicvet@gmail.com \\ ${ }^{4}$ Mestranda em Ciências Veterinárias, Centro de Ciências Agrárias e Engenharias, Universidade Federal do Espírito Santo - \\ Alegre/ES-Brasil-Email: jacydutra28@gmail.com \\ ${ }^{5}$ Docente do Departamento de Medicina Veterinária, Centro de Ciências Agrárias e Engenharias, Universidade Federal do \\ Espírito Santo-Alegre/ES-Brasil-.Email: cbmvt@hotmail.com \\ *Autor para correspondência
}

\begin{abstract}
RESUMO. As perdas gestacionais são problemas corriqueiros na equideocultura, sendo causa de preocupação entre os profissionais da área, gerando inúmeros prejuízos econômicos ao setor do agronegócio. As perdas gestacionais precoces são mais incidentes que tardias, sendo atribuídas a fatores maternais, ambientais e embrionários. Os fatores maternais incluem alterações de trato reprodutivo, idade da égua, deficiência de progesterona, momento da cobertura, estado reprodutivo, falha no reconhecimento materno da gestação, cobertura no cio do potro, entre outros. Aos fatores ambientais englobam estresse materno, nutrição e efeito do sêmen. As perdas de prenhez tardias são menos incidentes e foram atribuídas principalmente a desordens infecciosas relacionadas a interações feto-placentárias, como as placentites de origem ascendente. Herpesvírus equino tipo I e leptospirose são as causas infectocontagiosas mais comuns, tornando imprescindível o controle sanitário e a vacinação do plantel. Devido aos números alarmantes, objetivou-se nesse estudo, uma revisão de literatura descrevendo as principais causas de perdas gestacionais na espécie equina.
\end{abstract}

Palavras-chave: Abortamento, equino, perda embrionária

\section{Leading causes of pregnancy loss in the equine species: Review}

\begin{abstract}
The pregnancy loss are common problems in the creation of equine, being the cause of concern among professionals, the numerous economic losses to the agribusiness sector. Early miscarriages are more incidents late, being attributed to maternal, environmental and embryonic factors. The factors include maternal reproductive tract changes, the mare's age, progesterone deficiency, when the cover reproductive status, failure in maternal recognition of pregnancy covering the foal heat, among others. Environmental factors include maternal stress, nutrition and effect of semen. Late pregnancy losses are fewer incidents and were attributed mainly to infectious disorders related to fetal-placental interactions, as ascending placentitis of origin. Equine herpesvirus type I and leptospirosis are the most common infectious causes, making essential health control and vaccination of the squad. Due to the alarming figures, the aim of this study, a literature review describing the main causes of pregnancy loss in the equine species.
\end{abstract}

Key-words: Abortion, embryonic loss, equine

\section{Introdução}

A perda de prenhez é um dos principais fatores relacionados à subfertilidade na espécie equina, acarretando inúmeros prejuízos a pequenos e grandes produtores. Tanto problemas na gestação, quanto a ocorrência de perdas, estão 
significativamente relacionadas à saúde do trato reprodutivo materno (Guinter et al., 1985). A perda precoce do concepto na espécie equina ocorre entre 5 e $45 \%$ das gestações e de forma significativa, vêm afetando a eficiência reprodutiva do rebanho equino (Duarte, Vieira \& Silva, 2002). Segundo Brinsko et al. (2011), a perdas embrionárias estão relacionadas a problemas de origem materna, fetal e/ou ambiental. Watson (2000) relata que a endometrite é uma causa bastante corriqueira de perda embrionária precoce.

Rabelo et al. (2009) observaram um índice de perda de prenhez de $9,05 \%$ entre 15 e 45 dias pósinseminação. Resultados semelhantes foram encontrados por Taveiros et al. (2008), em que 879 éguas foram artificialmente inseminadas e dentre essas, $10,7 \%$ perderam concepto entre 16 e 45 dias de gestação. De acordo com Guinter et al. (1985), essas taxas são mais altas quando comparadas com as perdas em estágios gestacionais mais avançados.

A ocorrência de perda fetal após 50 dias de gestação ocorre em menor proporção, girando em torno de $8 \%$ (Pycock, 2008). No Brasil um estudo realizado no Paraná observou que $9,2 \%$ das perdas econômicas em criatórios de equinos foi devido a abortamentos (Moreira et al., 1998). Pereira (2012) ao analisar protocolos de necropsias observou uma taxa de 6,2 \% de abortamentos, sendo a maioria de origem bacteriana, seguida de causas virais e parasitárias. No entanto, segundo Brinsko et al. (2011) cerca de $60 \%$ dos casos de abortamento permanecem com etiologia desconhecida.

Devido à importância e aos prejuízos econômicos significantes que as perdas gestacionais ocasionam aos criadores de equinos, objetivou-se realizar uma revisão literária sobre as afecções mais comuns que resultam em perda de prenhez precoce e tardia na espécie equina.

\section{Causas de perdas gestacionais precoces}

\section{Endometrite}

Das afecções que acometem o sistema reprodutivo, as endometrites podem ser consideradas como uma das principais causas de subfertilidade e infertilidade na espécie equina (Grunert, Birgel \& Vale, 2005). A endometrite aguda é caracterizada pelo infiltrado de neutrófilos para o estroma do endométrio e luz uterina, pode ser de origem bacteriana ou não (Kenney, 1992). A forma mais comum é de endometrite pós- cobertura, inflamação uterina em resposta ao contato com o sêmen (Watson, 2000).

De acordo com a predisposição a inflamação endometrial, as fêmeas da espécie equina podem ser classificadas em dois grupos: éguas susceptíveis e éguas resistentes a endometrite, conforme a capacidade de resposta do seu sistema imune e sua capacidade uterina de debelar a inflamação (Watson, 2000). O sistema imunológico da égua deve ser capaz eliminar o fluido inflamatório em no máximo 96 horas, para que no quinto ou sexto dia após a fertilização, o embrião possa encontrar um ambiente propício ao chegar ao lúmen uterino (Woodwart \& Troedsson 2012). Caso isso não ocorra, uma inflamação persistente promove altas concentrações de prostaglandina, resultando em luteólise precoce, diminuição de progesterona e consequente perda embrionária (Adans et al., 1987).

Koblischke (2008) ao analisar a endometrite subclínica induzida por transferência de embriões em éguas observou que o grupo tratado com antiinflamatórios não esteroidais após a fertilização, apresentou diminuição nas concentrações de prostaglandina, e diminuição nas taxas de luteólise prematura. Woods (1987) obteve resultados semelhantes, observando ainda que éguas com histórico de endometrite demonstraram taxas superiores de perda embrionária quando comparadas a éguas sem histórico de endometrite.

Já a endometrite crônica possui como característica o fluxo de linfócitos para áreas do estroma endometrial, podendo ocorrer por contaminação espontânea, no momento do parto, estro, inseminação, ou em resposta a qualquer perturbação intrauterina (Kenney, 1992). No entanto, de acordo com Ball, Hillman \& Woods (1987), essa parece não interferir na evolução da gestação. Esses pesquisadores observaram que éguas subférteis portadoras de endometrite crônica, conseguiram manter o desenvolvimento embrionário, do mesmo modo que éguas sadias.

\section{Fibrose periglandular e cistos uterinos}

A Fibrose periglandular e os cistos uterinos têm sido considerados fatores de grande relevância quando se trata de perda de prenhez precoce na espécie equina (Vanderwall, 2008). E acomete principalmente éguas idosas (Doing, Mckninght \& Miller, 1981). As células estromais secretam componentes de matriz extracelular e fibronectina, contribuindo para o acúmulo desse material na região (Hoffmann et al., 2009). 
Acredita-se que na espécie equina a infertilidade associada à fibrose periglandular é consequência da falha de fixação do concepto (Ley, 2006).

Outra anormalidade uterina não inflamatória são os cistos uterinos. Segundo Ley (2006) eles podem ser classificados em cistos endometriais e linfáticos. Os endometriais são menores e se localizam em diversas regiões uterinas. Já os linfáticos são maiores e apresentam poucas localizações. Os cistos endometriais tornam-se nocivos à gestação a partir do momento em que ocorre um aumento exagerado no seu tamanho e quantidade. Cistos grandes podem interferir na movimentação do embrião, o que dificulta $o$ reconhecimento materno da gestação. Podem ainda, interferir na fixação da vesícula e em alguns casos afetar a placentação (Stanton, Steiner \& Pugh, 2004).

Tannus \& Thun (1995) ao analisarem 259 éguas férteis diagnosticaram em $22,4 \%$ delas a existência de cistos endometriais. Os tamanhos dos cistos variaram entre 3 e 48 milímetros, sendo o aumento no número de cistos observado no grupo com éguas de maior faixa etária. A taxa de prenhez nos dias 14 a 40 foram maiores no grupo em que as éguas apresentavam menores quantidades de cistos, sendo este o grupo mais jovem.

\section{Deficiência de progesterona}

Após a ovulação a produção de progesterona é decorrente do corpo lúteo primário, esse que se encontra maduro por volta do dia 5 após a ovulação e continua a crescer por volta do dia $35^{\circ}$ a $40^{\circ}$ após a ovulação quando a $\mathrm{eCG}$ (Gonadotrofina coriônica equina) começa a ser produzida pelos cálices endometriais. Nas éguas sua função ainda não está totalmente esclarecida, mas acredita-se que a eCG estimulem a formação de corpos lúteos acessórios, responsáveis por suplementar a produção de progesterona durante a gestação. Em torno do $100^{\circ}$ dia de gestação, os corpos lúteos acessórios regridem e a placenta passa a suprir a necessidade de progesterona para manutenção da gestação na égua (Prestes \& Alvarenga, 2006).

Segundo Vanderwall (2008), a deficiência de progesterona na égua, ocorreria devido à insuficiência de produção pelo corpo lúteo primário. Atualmente, nos programas de transferência de embriões, faz-se uso da administração de progestágenos exógenos (progesterona natural ou sintética) em receptoras de embriões. Após a confirmação da gestação, a aplicação dos progestágenos na receptora deve acontecer até o momento em que a unidade feto placentária esteja suficientemente madura e capaz de manter a gestação, com a produção de seus próprios progestágenos (Pinto, 2011).

Outra causa que promoveria a falha nas concentrações de progesterona foi descrita por Daels et al. (1987). Segundo os autores, os processos endotoxemicos de origem gastrintestinal ou exógenos nos equinos poderiam interferir na perda gestacional devido às altas concentrações de prostaglandinas produzidas em resposta a endotoxemia. $\mathrm{O}$ aumento de prostaglandina ocasionaria a luteólise precoce de corpo lúteo e consequente queda de progesterona endógena materna.

\section{Idade materna}

Não só na espécie equina, mas em outras, inclusive em humanos, a idade materna é questionada quanto a diminuição na capacidade de reprodutiva da fêmea. Woods et al. (1984), observaram que a única qualidade da égua estatisticamente associada a perda gestacional foi a idade. Esses resultados foram atribuídos a anormalidades uterinas e embrionárias, além da maior incidência de fibrose uterina predominante em éguas idosas. Resultados semelhantes foram obtidos por Tannus \& Thun (2010) ao analisarem a presença de cistos endometriais os autores constataram, uma maior quantidade desses cistos em éguas idosas, e concomitantemente esse grupo apresentou maior taxa de perda de prenhez. Davies et al. (2008), estudando 1380 éguas Puro Sangue Inglês com idade entre três e 28 anos, constataram que éguas velhas apresentavam maior incidência de gestação no corno uterino anteriormente gravídico, ocasionando maior taxa de perda gestacional precoce, devido ao aumento de tempo para involução uterina no corno anteriormente gravídico, sendo esse tempo de involução aumentado com a idade materna.

Diversos estudos colocam em questão a viabilidade de embriões de éguas idosas (Vanderwall, 2008). Ball et al. (1989) ao coletarem embriões de éguas jovens e idosas e transferirem para éguas jovens, observaram que a taxa de sobrevivência de embriões de éguas jovens foram significativamente maiores $(84 \%)$ que de éguas velhas (25\%). Os mesmos resultados foram obtidos por Carnevale \& Guinter (1995), onde os oócitos de éguas jovens e velhas foram retirados 
via aspiração folicular guiada por ultrassom e transferidos cirurgicamente para o oviduto de éguas jovens. A fertilização e desenvolvimento nas receptoras jovens permitiram minimizar os efeitos do ambiente uterino de éguas velhas. Por meio da ultrassonografia transretal os autores observaram que a taxa de formação de vesícula embrionária foi superior em éguas jovens (92\%) quando comparado às éguas idosas (31\%).

\section{Lactação}

De acordo com Grunert, Birgel \& Vale (2005) existe influência negativa da lactação na implantação do concepto. Acredita-se que ocorra uma competição energética entre a produção de leite e a manutenção do embrião.

Rabelo et al. (2009) ao analisarem as taxas de perda embrionária em éguas da raça Mangalarga Machador, observaram que as éguas pluríparas lactantes foram as que apresentaram menor desempenho reprodutivo. No entanto, Taveiros et al. (2003) ressaltam não haver diferenças entre os índices de fertilidade de éguas receptoras núliparas, pluríparas lactantes ou pluríparas não lactantes. Em contrapartida, é apontada a existência de uma relação mais próxima entre estado nutricional do animal com a sobrevivência do embrião, do que com a lactação (Hnneke, Potter \& Kreider, 1984).

\section{Cobertura no cio do potro}

Após o parto as éguas apresentam uma rápida involução uterina, resultando em retorno a condição pré parto possibilitando manifestações rápidas de cios férteis. $\mathrm{O}$ cio do potro é o primeiro cio após a parição e ocorre em média sete dias pósparto (Brinsko et al., 2011). Ou em até 18 dias após o parto (Davies Morel, 2003). Fiolka, Kuller \& Lender (1985), observaram que a taxa de perda de prenhez precoce nas 2.533 éguas estudadas foi de $7,2 \%$. As perdas em fertilizações ocorridas no cio do potro, obtiveram uma taxa de $11,6 \%$, segundo eles isso seria decorrente de involução incompleta do útero no pós-parto. Esses achados se assemelham ao de Meyers, Bonnett \& Mckee (1991) que ao observarem que éguas cobertas no cio do potro são 1,9 vezes mais propensas à perda gestacional precoce, do que éguas em outros estados reprodutores. Em contrapartida, a utilização do cio do potro foi considerada vantajosa por Reiner, Yunes \& Reiner (1988) principalmente pela agilização da estação de monta. Estes autores utilizando o cio do potro obtiveram um índice de prenhez de 47,40\% e perda gestacional precoce de $13,5 \%$. Azevedo et al. (2003) ao testarem a eficiência reprodutiva de receptoras no cio do potro quando submetidas a transferência de embriões, constaram que a eficiência reprodutiva dessas éguas foi semelhante a éguas de cios subsequentes. As taxas de gestação e perda embrionária não diferiram. Resultados condizentes foram obtidos por Carvalho et al. (2001) onde não se observou diferença de recuperações de embriões em éguas no cio do potro comparas a éguas solteiras. Os mesmos indicam a utilização do cio do potro visando o maior proveito da estação de monta.

$\mathrm{O}$ mesmo posicionamento quanto à utilização do cio do potro foi relatado por Souza, Toledo \& Lima (2001) ao investigarem a ocorrência de perda embrionária precoce em 928 gestações em éguas da raça Mangalarga, concluíram que se pode indicar a utilização do cio do potro como uma prática de manejo adequada em programas de reprodução.

\section{Momento da inseminação em relação à ovulação}

O espermatozoide pode permanecer viável entre 48 a 72 horas no trato reprodutor da fêmea, enquanto o óvulo de seis a 18 h após a ovulação. Desse modo a distância do momento da ovulação, pode interferir na taxa de concepção da égua (Vanderwall, 2008).

Koskinen et al. (1990), ao investigarem a taxa de concepção em 28 éguas cobertas entre zero e 27 h pós ovulação, observaram que $46 \%$ dessas éguas estavam prenhas. Dentre estas, ocorreram cinco casos de perda embrionária, levando a diminuição da taxa de prenhez para 29\%. Assim, os autores chegaram a conclusão que o óvulo permaneceu em boas condições de ser fecundado até $18 \mathrm{~h}$ após a ovulação, mas a devido a alta incidência de perdas embrionárias, os autores inferiram que a viabilidade do embrião foi diminuída pela fecundação tardia do ovócito. Ferraz \& Vicente (2006) chegaram a resultados semelhantes ao analisarem a influência do momento da cobertura, em relação à ovulação na fertilidade e ocorrência de morte embrionária, constataram que a incidência de concepção aumentou à medida que a cobertura ocorria próximo de $12 \mathrm{~h}$ antes da ovulação e a perda embrionária diminuiu à medida que ocorria próximo da ovulação. Woods et al. (1990) atribui a maior taxa de perda embrionária a medida em que o tempo de cobertura se afasta do momento da ovulação devido ao envelhecimento do ovócito. 
Hunter (1990) levantou a hipótese de os gametas conservarem a capacidade de serem fertilizados por mais tempo, no entanto, o ambiente uterino poderia não estar propício à implantação do embrião quando a fertilização ocorresse distante da ovulação. No entanto, Krackow (1997), relata assincronia do desenvolvimento de embriões masculinos e femininos, propondo que fatores hormonais ou alterações no ambiente uterino influenciariam as taxas de concepção e de morte embrionária.

\section{Falha no reconhecimento materno da gestação}

Nos equinos, o reconhecimento materno da gestação ocorre pela movimentação do embrião no útero materno que garante o sinal de reconhecimento da gestação por toda extensão uterina, levando a supressão da liberação cíclica da prostaglandina pelo endométrio. Esta movimentação do embrião é possível devido a cápsula glicoproteica que o envolve. A movimentação persiste até aproximadamente 16 ou 17 dias após a ovulação, quando ocorre um rápido aumento no diâmetro do embrião e aumento do tônus uterino, fazendo com que o concepto se implante em um dos cornos uterinos (Prestes \& Alvarenga, 2006).

Outra diferença do reconhecimento gestacional equino é a habilidade do embrião em secretar prostaglandinas E2, essa que não tem acesso a corrente sanguínea, portanto, não compromete a viabilidade do corpo lúteo. Acredita-se que a liberação de prostaglandina E2 promova contrações peristálticas e relaxamento do miométrio contribuindo para fixação do concepto (Stout \& Allen, 2001).

Uma taxa elevada de perda gestacional na égua ocorre devido a falha na liberação de fatores que promovem o reconhecimento materno da gestação pelo concepto. Dessa forma, não ocorre sinalização para o corpo materno e se tem liberação de prostaglandina $\mathrm{F} 2 \alpha$, que atinge a circulação e promove a luteólise do corpo lúteo (Allen, 2001).

\section{Local de implantação da vesícula embrionária}

Entende-se por implantação da vesícula embrionária o contato físico entre embrião $\mathrm{e}$ endométrio, após a dissolução da zona pelúcida. $\mathrm{Na}$ espécie equina a implantação ocorre em aproximadamente 30 a 35 dias após a fertilização (Prestes \& Alvarenga, 2006). Embora seja raro, a vesícula embrionária pode se implantar em locais bastante incomuns do trato reprodutivo (Vanderwall, 2008).

Em um estudo realizado por Jobert, Leblanc \& Pierce (2005) analisando 30 gestações no corpo uterino, das quais nove estavam localizadas mais cranialmente e 21 mais próximas da cérvix. Sete dos embriões localizados mais cranialmente conseguiram levar a gestação até o final e dois morreram entre 35 e 42 dias. Dentre as 21 localizadas próximas a cérvix três foram eliminadas pela utilização de PGF2 $\alpha$ e das 18 restantes, apenas 3 chegaram a termo.

\section{Alterações cromossomais maternas}

Algumas anormalidades cromossômicas são descritas em equinos como a disgenesia gonadal na égua e a Síndrome da reversão sexual XY, que estão relacionadas à ausência de atividade cíclica nas éguas portadoras e não diretamente a perda de prenhez (Grunert, Birgel \& Vale 2005).

Lear et al. (2008) relataram três casos de translocações autossômicas relacionadas a perda embrionária em éguas com perdas gestacionais repetidas por volta de 65 dias de gestação. Porém, esses três animais apresentaram ciclos estrais normais e uma delas já havia produzido dois potros antes da perda gestacional relatada. Os autores relacionaram essas perdas a alterações cromossomais sutis, já que dependendo da segregação gênica e segregação cromossômica seguindo a meiose podem levar a produção de gametas alterados. Os autores enfatizaram a importância de cariotipar éguas aparentemente subférteis para verificar possíveis anormalidades cromossômicas.

\section{Estresse}

O estresse materno foi proposto como um contribuinte para a ocorrência de perda embrionária precoce na espécie equina (Vanderwall, 2008). Segundo Brinsko et al. (2011), ocorre uma significativa diminuição nas concentrações de progesterona decorrente do excesso de cortisol. Em estudo realizado por Van Niekel \& Morgenthal (1982) ao administrar 150 $\mathrm{mg}$ de prednisolona em duas éguas gestantes observaram níveis altos, porém transitórios nas concentrações de progesterona (cerca de 30\% a $40 \%)$.

Um estudo subsequente realizado por Baucus et al. (1990) ao avaliar 54 éguas transportadas durante nove horas observaram que o estresse pelo transporte induziu alterações no nível sérico de 
cortisol e progesterona, porém não houve nenhuma ocorrência de perda gestacional.

Newcobe \& Wilson (2005) sugeriram a interferência do estresse social quando éguas eram recém-inseridas no rebanho como fator predisponente para perda gestacional. Daels et. al (1987) Induzindo estresse fisiológico em éguas por aplicação endovenosa de Salmonella typhimuruim para que se instale uma endotoxemia, observou que 7 das 9 éguas tratadas apresentaram perdas gestacionais, essas éguas apresentavam-se entre os dias 23 e 55 pós gestação.

\section{Nutrição}

O estado nutricional está intimamente relacionado a respostas fisiológicas adequadas em todos os organismos vivos. Sabe-se que quando a nutrição é falha, uma das respostas do organismo é cessar a reprodução (Brinsko et al. 2011).

Newcobe \& Wilson (2005) observaram que $71 \%$ das éguas que mantiveram prenhez, ganharam peso durante a temporada reprodutiva, enquanto, as éguas que apresentaram perda de prenhez (58\%) entre 14 e 45 dias, perderam peso durante a gestação. Esses resultados coincidem com os obtidos em experimentos que avaliaram a perda embrionária relacionada à lactação. Henneke et al. (1984) sugerem que exista uma relação mais próxima entre estado nutricional do animal com a sobrevivência do embrião, do que com a lactação. Os mesmos autores ao avaliarem éguas que perderam peso, detectaram que as éguas com baixa condição corporal apresentaram uma taxa de $75 \%$ de perda embrionária contra 0 a $12 \%$ no grupo que manteve o escore corporal.

Fatores relacionados ao sêmen e considerações sobre as biotecnologias da reprodução

Diversos autores questionam a influência das biotecnologias da reprodução no aumento da incidência de perda embrionária em éguas. Squires, Mckinnon \& Shideler (1988) atribuíram as perdas embrionárias nos programas de transferência de embriões (TE) a uma variabilidade de fatores, inclusive o método de transferência. Eulálio et al. (2013) avaliaram as características cíclicas da égua receptora, constatando que éguas com fase folicular maior que sete dias, apresentava maior incidência de perda gestacional. Alonso et al. (2005) correlacionam as altas taxas de morte embrionária em programas de transferência de embriões com o comprometimento da difusão da técnica no mercado de reprodução equina. Quando a técnica utilizada é a Inseminação Artificial (IA), Villahoz (1985), avaliou as taxas de perdas gestacionais utilizando sêmen fresco e congelado, atentou para maiores taxas de perda embrionária em éguas inseminadas com sêmen congelado $(34,6 \%$, contra $15,8 \%$ ). Porém, esse mesmo autor em um segundo experimento utilizando métodos de congelamento de sêmen mais aprimorados não obteve diferenças significativas quanto à ocorrência de perda de prenhez entre sêmen fresco e congelado. Resultados semelhantes aos obtidos por Squires, Mckinnon \& Shideler (1988) mostram que o sêmen é um fator importante a ser considerado. Em um estudo comparando TE com IA os autores verificaram que os animais submetidos à transferência de embriões apresentaram uma taxa de perda de prenhez de 13,3\%, o que não diferiu quando comparadas a de éguas submetidas a IA com sêmen fresco $13,4 \%$. Porém, quando essas éguas foram inseminadas com sêmen congelado a taxa foi significativamente maior. A interferência dos métodos de reprodução também foi estudada por Souza, Toledo \& Lima (2001), que ao investigarem a interferência dos métodos de acasalamento (Inseminação artificial com sêmen fresco e monta natural), em éguas com diferentes estados reprodutivos concluíram que as éguas submetidas a IA apresentaram maiores taxas de perda embrionária quando comparadas a éguas submetidas à monta natural. A fim de comparar as taxas de perda de concepto em programas de Inseminação artificial e transferência de embrião, Taveiros et al. (2008) analisaram 340 éguas submetidas a TE e IA. Obtiveram taxas de perda de prenhez de $10,7 \%$ nas éguas submetidas a IA, e $11,7 \%$ nas éguas submetidas a TE. Concluíram que após a implantação e o desenvolvimento embrionário, as causas da perda independem da técnica reprodutiva utilizada.

\section{Causas de perdas gestacionais tardia em éguas}

\section{Herpesvirus equino tipo I}

O herpesvirus equino tipo 1 (HEV-1) é descrito como a mais importante causa de abortamento de origem infecciosa (Acland, 1987).

No Brasil, Nilsson \& Corrêa (1966) isolaram pela primeira vez o vírus do aborto viral equino em hamsters lactantes, a partir do fígado do feto abortado. O HEV-1 é um vírus envelopado pertencente à subfamília Alphaherpesviridae e são identificados os subtipos: subtipo 1: causador de 
aborto, doença respiratória e doença neurologia e o subtipo 2: causador de doença respiratória e raramente perda gestacional (Studdert \& Blackney, 1979). Trabalhos mais atuais os classificam como herpesvirus equino tipo 1: responsável principalmente pelo aborto equino e herpesvirus equino tipo 4: responsável principalmente pela rinopneumonite equina (Fitzpatrick \& Studdert ,1984).

Segundo Brinsko et al. (2011) os animais infectados apresentam perda de prenhez geralmente no terço final da gestação. Normalmente a perda do feto ocorre de forma rápida, sem sinais alarmantes e no exame clínico as éguas não demonstram alterações. As fontes de disseminação viral são a via respiratória, fetos abortados e fluidos fetais (Osthund, Powell \& Bryan 1991).

Laugier et al. (2011) investigando
abortamentos durante 24 anos na França,
observaram que $14,5 \%$ dos casos de perdas
gestacionais tardias estavam associados a
infecções por HEV-1. As éguas acometidas
podem permanecer assintomáticas ou apresentar
sinais de infecção somente quando submetidas a
condições de estresse (Wilson, 1997). Moreira,
Weiss \& Kruger (2000) ao testarem a incidência
de contaminação por HEV-1 em equinos
aparentemente sem sinais de infecção, através de
titulação de anticorpos, obtiveram em um total de
229 amostras de soro sanguíneo de animais não
vacinados contra rinopneumonite, 53 (17,7\%)
positivos para hespesvírus equino tipo 1. Cunha et
al. (2002) verificaram equinos sorologicamente
positivos em rebanhos não vacinados, o índice de
equinos apresentando anticorpos contra HVE-1,
apresentou-se superior ao trabalho descrito
anteriormente, sendo que a taxa de animais
soropositivos foi de $27,2 \%$.

Weiblen et al. (1994) relatam um surto de perda de prenhez devido a HEV-1 em cinco éguas entre 9 e 11 meses de gestação pertencentes a um plantel equino de 22 éguas Puro Sangue Inglês no Rio Grande do Sul, Brasil. De acordo com Acland (1987) as infecções e os casos de perdas gestacionais são menos comuns em rebanhos em que não há entrada de novos animais após o primeiro trimestre de gestação. Moreira et al. (1998) também isolaram HEV-1 ao analisar material de 21 fetos abortados, confirmando a infecção por HEV-1 em 4 amostras totalizando $8 \%$ dos casos. Em 54\% dos abortamentos analisados neste estudo a etiologia não foi identificada, $34 \%$ foram de origem bacteriana e $4 \%$ decorrentes de gestação gemelar.

\section{Leptospirose}

A leptospirose é uma zoonose bacteriana, causada por vários sorovares da espécie Leptospira interrogans. A infecção acontece pela pele e mucosas que entram em contato com urina, fluidos placentários, alimentos contaminados, e ainda pode ser transmitida pelo sêmen e por via transplacentária (Girio \& Lemos, 2007). Os roedores são os principais reservatórios e a sazonalidade da doença está relacionada a épocas chuvosas e de alagamento (Batista, 2004).

A infecção por Leptospira sp. em equinos, normalmente é subclínica e os abortamentos ocorrem no terço final da gestação. $\mathrm{O}$ abortamento é decorrente da leptospiremia fetal, que é a passagem das leptospiras através da placenta (Vasconcelos, 2000). Quando não ocorre a perda gestacional, os fetos podem nascer fracos e prematuros (Girio \& Lemos, 2007). A forma clínica da doença pode ocasionar febre, icterícia, problemas oculares como uveíte progressiva e morte por nefrite intersticial (Hong et al., 1993).

Abachaim (1991) avaliando soros de 420 equinos em municípios do Rio Grande do Sul constatou que $37,4 \%$ deles apresentavam titulação positiva e $55,6 \%$ dos animais apresentavam-se clinicamente sadios, podendo ser fonte de contaminação para o homem e outros animais.

Pereira et al. (2012) observaram um índice de $5,6 \%$ de abortos confirmados por leptospirose. Pescador et al. (2004) relataram a ocorrência de abortamentos esporádicos em uma propriedade. $\mathrm{O}$ último feto abortado apresentando em torno de 6 meses de gestação foi necropsiado e encontradas lesões renais, hepáticas, dentre outras, características de leptospirose. Os autores descreveram a importância da investigação dos casos de aborto e vacinação do plantel, já que no presente relato os animais não eram vacinados contra leptospirose.

\section{Placentites}

A contaminação no trato genital das éguas é causada normalmente devido ao fechamento insuficiente da vulva e vestíbulo associados principalmente a deficiência de conformação perineal. Como consequência, a via ascendente (cervical) é a forma mais comum de infecções (Brinsko et al., 2011). A placentite é um dos principais problemas que comprometem a 
gestação (Pycock, 2008). E refere-se à inflamação de origem infecciosa nas vilosidades corioalantoidianas podendo acometer âmnio e cordão umbilical. Podem ocasionar abortamentos e partos prematuros com nascimento de potros inviáveis e letárgicos (Brinsko et al., 2011). Além da ação do agente infeccioso, o processo inflamatório resulta na produção de prostaglandinas que atuam na estimulação da contração do miométrio levanto a expulsão fetal (Troedsson \& Macpheron, 2011). A sintomatologia clínica mais comum é aumento precoce das mamas, gotejamento de leite descolamento de placenta, prurido perineal, desconforto abdominal, secreção vaginal (Whitwell, 2011) e relaxamento da cérvix (Pycock, 2008). Os microorganismos mais comumentes descritos como causadores de placentites bacteriana são: Streptococcus zooepidermicus. Escherichia coli, Klebsiella pneumonia e Pseudomonas aeruginosa (Acland, 1993; Troedsson \& Macpherson, 2011). A placentite fúngica na égua é esporádica e ocorre pela contaminação via cérvix, já que a placenta epiteliocorial impossibilita o contato do agente infeccioso pelas vias respiratórias e digestivas (Banks, 1992).

A maior incidência da infecção ocorre em épocas que os animais ficam durante muito tempo estabulados, aumentando as possibilidades de contaminação via vaginal (Driemeier et al., 1998). Aspergillus fumigatos é o fungo mais comumente isolado, Driemeier et al. (1998) e Peres et al. (2008) relataram casos de placentite micótica, seguido de abortamento causado por Aspergillus fumigatos.

\section{Gestação gemelar}

A geminação é uma condição indesejável na égua, se uma das gestações não é interrompida no início, o resultado é o abortamento tardio (Brinsko et al., 2011). A utilização da ultrassonografia na medicina equina possibilitou o diagnóstico precoce de gestação gemelar, e possível intervenção precoce para a finalização de uma das gestações. São diversos os métodos utilizados para tal, como a terapia com prostaglandinas, esmagamento mecânico de corpo lúteo, entre outros (Ley, 2006). Fiala et al. (2003) obtiveram sucesso provocando a destruição mecânica da vesícula embrionária por esmagamento, antes ou após a fixação uterina.

\section{Torção uterina}

A torção do útero durante a gestação ocorre ocasionalmente na espécie equina, entre 5 a 9 meses de gestação, causando sérias complicações. Torções maiores que 180 graus, levam a sinais de cólica persistentes que são facilmente confundidos com problemas intestinais, sendo indispensável o diagnóstico por palpação transretal (Macpherson, 2011).

As alterações de fluxo sanguíneo levam a hipóxia e morte fetal, e o abortamento ocorre em alguns dias (Brinsko et al., 2011). As torções maiores que 270 graus podem levar a ruptura uterina com perda de feto na cavidade abdominal (Pycock, 2008). A correção das torções deve ser cirúrgica por meio de laparotomia mediana ventral, ou pelo flanco (Macpherson, 2011), porém, segundo Brinsko et al. (2011) existem casos em que a torção é corrigida, o feto está vivo e a perda gestacional ocorre cerca de duas semanas depois.

\section{Torção de cordão umbilical}

Os fetos que morrem devido à obstrução vascular do cordão umbilical, não são abortados imediatamente. Quando abortados, os tecidos apresentam graus variáveis de autólise. Algumas alterações não específicas como abdômen distendido, líquido sanguinolento nas cavidades e as vezes edema em volta do umbigo são observados (Whitwell, 2011).

\section{Ruptura do tendão pré-púbico e hérnia da parede abdominal}

A ruptura do tendão pré-púbico é uma anormalidade gestacional que ocorre no final da gestação acometendo na maioria dos casos éguas gestando fetos grandes, gêmeos e éguas com hidroalantóide devido ao aumento da tensão abdominal (Brinsko et al., 2011). As éguas acometidas apresentam sinais de desconforto abdominal, tornam-se relutantes em se mover, assumem posição característica de cavalete (tuberosidade isquiática e cauda arqueadas), as glândulas mamárias podem se deslocar cranialmente. O diagnóstico por palpação retal é dificultado devido a gestação avançada, e a ultrassonografia é a melhor forma de diagnóstico e avaliação da viabilidade fetal (Rodgerson, 2011). Éguas com ruptura de tendão pré-púbico, dependendo da sua condição clínica, podem ser capazes de levar a gestação até o final, porém, é necessário acompanhamento gestacional e 
assistência do parto. Esses animais devem ser retirados da reprodução, pois em uma gestação seguinte provavelmente apresentarão ruptura completa do tendão (Macpherson, 2011). É necessária a intervenção para diminuir a tensão na musculatura evitando assim, ruptura da parede abdominal, controle do processo inflamatório e da dor sendo assim de grande valia a utilização de envoltórios abdominais, concomitantemente com terapia anti-inflamatória e analgésica (Rodgerson, 2011). Em alguns casos devido às condições clínicas da égua é estritamente necessária a indução do parto para evitar a perda do feto (Pycock, 2008). Uma condição similar é a formação de hérnia na parede abdominal, no entanto, a hérnia apresenta menores riscos ao feto, o prognóstico depende da gravidade da hérnia podendo ser feita em alguns casos correção cirúrgica após o nascimento (Brinsko et al., 2011). Devido à diminuição nas contrações uterinas deve ser feito a indução e acompanhamento do parto em condições de maturidade fetal (Macpherson, 2011).

\section{Hidroalantóide}

A hidropsia das membranas fetais, alantoidiana e amniótica, são condições raras na égua, porém conhecidas mundialmente. $\mathrm{O}$ hidroalantóide, que é o acúmulo de líquido na membrana alantoideana é a mais comum, ocorrendo normalmente entre 6 a 7 meses de gestação e em associação com anormalidades placentárias, posições fetais anormais e parto gemelar (Waelchli, 2011; Brinsko et al., 2011). O hidroalantóide é caracterizado pelo aumento repentino no fluido alantoidiano levando a distensão abdominal nas éguas acometidas, os animais também apresentam sintomatologia clínica sistêmica (Waelchli, 2011). Devido ao aumento de volume abdominal, a égua se torna predisposta à ruptura de tendão prépúbico, distensão uterina e hérnia abdominal (Brinsko et al., 2011). O abortamento espontâneo é uma sequela comum de hidroalantóide e inúmeras vezes complicam-se pela inércia na musculatura uterina. A condição da égua deve ser avaliada necessitando a indução do parto como forma de tratamento para evitar complicações. Fetos provenientes de gestação com hidroalantóide podem nascer com anormalidades congênitas principalmente relacionadas a alterações encefálicas (Waelchli, 2011). Para se chegar à confirmação deve ser feio o diagnóstico diferencial para outros processos patológicos que causam aumento de volume abdominal no terço final da gestação. A palpação abdominal é o exame mais utilizado e possibilita avaliar a extensiva presença de líquido fetal, assim como a ultrassonografia transabdominal (Pycock, 2008).

\section{Considerações finais}

É imprescindível a investigação das causas de perda de prenhez em éguas, para que se possa prevenir novas ocorrências e diminuir o prejuízo ao criador. A ultrassonografia é o exame complementar de maior valia no diagnóstico de perda gestacional precoce. $\mathrm{O}$ exame ginecológico por meio da palpação transretal é o exame mais indicado para detecção de perda gestacional tardia. São necessárias práticas de manejo adequadas como higiene sanitária e a vacinação do plantel contra as principais enfermidades. Deve-se evitar introdução de novos animais no rebanho sem quarentena; as biotecnologias realizadas por profissionais capacitados; éguas destinadas à reprodução devem ter acompanhamento regular, e sempre que diagnosticado alguma alteração que denote risco materno ou fetal, o tratamento deve ser realizado por um médico veterinário. $\mathrm{O}$ feto e placenta devem ser considerados materiais de risco para contaminação de novos animais, devendo ser manejados e descartados de forma adequada.

\section{Referências Bibliográficas}

Abachaim, D.M. 1991. Presença de aglutininas anti-Leptospira em soro de equinos no Estado do Rio Grande do Sul. Acta Scientiae Veterinary, 19, 9-14.

Acland, H.M. 1987. Abortion in mares: diagnosis and prevention. Compendium Equine, 9, 38324.

Acland, H.M. 1993. Abortion in mares. In: McKinnon, A.O.; Voss, J.L. Equine Reproduction. Lea and Febiger, Philadelphia. USA.

Adans, G.P., Kastelic,J.P., Bergfelt, D.R., Ginther,O. 1987. The Effect of uterine inflammation and ultrasonically detected uterine pathology on fertility in the mare. Journal of Reproduction and Fertily, 35, 445454.

Allen, W.R. 2001. Luteal Insufficiency and embryo mortality in the mare. Reproduction in Domestic Animals, 36, 121-131.

Alonso, M.A., Fleury, P.D.C., Neves Neto, J.R., Machado, M.S. 2005. Effect of donor mare's 
age in embryonic loss rate. Acta Scentiae Veterinariae, 33, 203-209.

Assis brasil, N., Frey JR., F., Silveira, P.S., Ladeira, S., Soares, M.P., Schild, A.N. 2007. Causas de abortos em equinos PSI na região de influência do laboratório regional de diagnóstico In: XVI congresso de iniciação científica e IX encontro da pós-graduação. 2007. Pelotas, RS. Anais... Pelotas, RS.

Azevedo, R, P., Mendonça, L.A., Lanza, J.C., Lopes, E.P., Gomes, P.S., Valle, G.R. 2003. Eficiência reprodutiva em transferências de embriões equinos utilizando receptoras no cio do potro. Revista Brasileira de Reprodução Animal, 37, 365-370.

Ball, B.A., Hillman, R.B., Woods, G.L. 1987. Survival of equine embryos transferred to normal and subfertile mares. Theriogenology, 28, 611-619.

Ball, B.A.,Little, T.V., Weber, J.A., Woods, G.L. 1989. Survival of day-4 embryos from young, normal mares and aged, subfertile mares after transfer to normal recipient mares. Journal of Reproduction and Fertily, 85, 187-194.

Banks, W. J. 1992. Histologia veterinária aplicada. Manola, São Paulo, Brasil.

Batista, C. S. A. 2004. Soroprevalência de leptospirose em case errantes da cidade de Patos, Estado da Paraíba, Brasil. Brazilian Journal of Veterinary Research and Animal Science, 41, 131-136.

Baucus, K. L., Ralston, S. L., Nockels, C. F., Mckinnon, A. O. \& Squires, E. L. 1990. Effects of transportation on early embryonic death in mares. Journal Animal Science, 38, 345-351.

Brinsko, S. P., Blanchad, T. L., Varner, D. D., Scgumacher, J., Love, C. C., Hinrichs, K. \& Hartman, D. 2011. Manual of equine reproduction, Mosby Elsevier, USA.

Carnevale, E. M. \& Guinter, O. J. 1995. Defective oocystes as a cause of subfertily in old mares. Biology of Reproduction Mono, 1, 209-214.

Carvalho, R. C., Fonseca, F. A., Silva Filho, J. M., Ruas, J. R. M. \& Borges, A.M. 2001. Avaliação da utilização do "Cio do Potro" na coleta de embriões. Revista Brasileira de Zootecnia, 30, 1145-1150.

Cunha, E. M. S., Ferrari, C. I. L. \& Silva, L.N.Q. 2002. Presença de anticorpos contra o herpesvirus equino tipo 1 (HVE-1) em equinos do noroeste do estado de São Paulo. Arquivo do Instituto Biológico, 69, 1-5.

Daels, P.F., Starr, M., Kindahl, H., Fredriksson, G. \& Hughes, J.P., Stabenfeldt, G.H. 1987. Effect of Salmonella typhimurium endotoxin on PGF2 $\alpha$ release and fetal death in the mare. Journal of Reproduction and Fertility, 35, 485492.

Davies Morel, M. C. G. 2003. Equine reproductive physiology, Breeding and stud management, País de Gales.

Davies Morel, M. C. G., Newcombe, J. R. \& Hinchliffe J. 2008. The relationship between consecutive pregnancies in Thoroughbred mares. Does the location of one pregnancy affect the location of the next, is this affected by mare age and foal heat to conception interval or related to pregnancy success. Theriogenology, 71, 1072-1078.

Doing, P. A., Mckninght, J. D. \& Miller, R.B. 1981. The use of endometrial biopsy in the infertile mare. Canadian Veterinary Journal, 22, 72-76.

Driemeier, D., Finges, G. P., Rocha, A. L., Garbade, P., Rodrigues, J. D. \& Costa Mattos, R. Aborto e Placentite Micótica por Aspergillus fumigatus em uma égua.1998. Ciência Rural, 28, 321-324.

Duarte, M. B., Vieira, R. C. \& Silva, F.O.C. 2002. Incidência e perda de prenhez até 50 dias em éguas Quarto de Milha. Ciência Rural, 32, 543647.

Eulálio, N. C., Borges, L. M., Lopes, E. P., Gomes, P. S. \& Valle, G. R. 2013. Taxas de perda gestacional até 60 dias são afetadas por características cíclicas da égua receptora de embrião Mangalarga Machador. Revista Brasileira de Medicina Veterinária e Zootecnia, 65,397-403.

Fernandes, W. R. \& Souza, M. C. C. 1999. Determinação sorológica da artrite viral equina em equinos hígidos, com abortamento e com sintomas de alteração do sistema respiratório. Revista Brasileira de Ciência Veterinária, 6, 147-150.

Ferraz, L. E. S. \& Vicente, W. R. R. 2006. Influência do momento de cobrição em relação à ovulação, na fertilidade e na ocorrência de morte embrionária precoce em equinos. Revista Brasileira de Medicina Veterinária e Zootecnia, 58,537-543. 
Fiala, S. A., Trein, C. R., Meirelles, L. S., Malschitzky, E., Garbade, P., Gregory, R. M. \& Mattos, R. C. 2003. Redução da gestação gemelar em éguas Puro Sangue de corrida antes ou após a fixação uterina da vesícula embrionária. Acta Scientiae Veterinariae, 31, 145-148.

Fiolka, G., Kuller, H. J. \& Lender, S. 1985. Embryonic mortality in the horse. Monatshefte-fur-Veterinarmedizim, 40, 835838.

Fitzpatrick, D. R. \& Studdert, M.J. 1984. Immunologic relationships between equine herpesvirus type 1 (equine abortion virus) and type 4 (equine rhinopneumonitis virus). Americam Journal of Veterinary Research, 45, 1947-1952.

Giles, R. C., Donahue, J. M., Hong, C. B., Tuttle, P. A., Petrites-Murphy, M. B., Poonacha, K. B., Roberts, A. W., Tramontin, R. R., Smith, B. \& Swerczek, T. W. 1993. Causes of abortion stillbirth, and perinatal death in horses: 3.527 cases (1986-1991). Journal of the American Veterinary Medical Association, 203, 11701175.

Ginther, O. J., Garcia, M. C., Bergfelt, D. R., Leith, G. S. \& Scraa, S.T. 1985. Embryonic loss in mares: Pregnancy rate, length of interovulatory intervals, and progesterone concentrations associated with loss during days 11 to 15 . Theriogenology, 24, 203-216.

Girio R. J. S. \& Lemos R. A. A. 2007. Doenças de ruminantes e equídeos. In: Riet-Correa, F.; Schild, A.L.; Lemos, R.A.A., Borges, J.R.J. Doenças Bacterianas, Leptospirose.Santa Maria: Pallotti, Santa Maria, Brasil.

Grunert, E., Birgel, E. H. \& Vale, W. G. 2005. Patologia e clínica da reprodução dos animais mamíferos domésticos: ginecologia. Varela, São Paulo, Brasil.

Henneke, D. R., Potter, G. D. \& Kreider, J. L. 1984. Body Condition during pregnancy and lactation and reproductive efficiency of mares. Theriogenology, 21, 897-909.

Hoffman, C., Ellenberger, C. \& Mattos, R. C. 2009. The equine endometrosis: New insights into the patogenesis. Animals Reproduction Science, 111, 261-278.

Hong, C. B., Donahue, J. M., Giles JR, R. C., Petrites-Murphy, M. B., Poonacha, K. B., Roberts, A. W., Smith, J., Tramonth, R. R.,
Tuttle, P. A. \& Swerczek, T.W. 1988. Equine abortion and stillbirth in central Kentucky during 1988 and 1989 following seasons. Journal Veterinary Diagnostic Investigation. 5, 560-566.

Hunter, R. H .F. 1990. Gamete lifespans in the mare's genital tract. Editorials.Equine Veterinary Journal, 22, 378-379.

Jobert, M. T., Leblanc, M. M. \& Pierce, S. W. 2005. Pregnancy loss rate in equine uterine body pregnancies. Equine Veterinary Education, 17, 163-165.

Kenney, R. M. 1992. The etiology, diagnosis and classifications of chronic degenerative endometrits. Equine Veterinary Journal, 25, 185-186.

Koblischeke, P. 2008. Embryo transfer induces a subclinical endometritis in recipient mare which can be prevented by treatment with nonsteroid-inflammatory drugs. Theriogenology, 70, 147-1158.

Koskinen, E., Lindeberg, H., Kuntsi, H., Ruotsalainen, L. \& Katila, T. 1990. Fertility of mares after postovulatory insemination. Zentralbl Veterinar Medicine, 37, 77-80.

Krackow, S. 1997. Further evaluation of the developmental asynchrony hypothesis of sex ratio variation. Applied Animals Behaviour Science, 51, 243-250.

Laugier, C., Foucher, N., Sevin, C., Leon, A. \& Tapprest. J. 2011. A 24-year retrospective study of equine abortion in Normandy (France). Journal Equine Veterinary Science, $31,16-123$.

Lear, T. L., Lundquist, J., Shideler, R. R., Tarr, S. F. \& Nett, T. M. 2008. A three autosomal chromosome translocations associated with repeated early embryonic loss (REEL) in the domestic horse (Equus caballus). Cytogenetic and Genome Research, 120, 117-122.

Ley, W. B. 2006 Reprodução em éguas: Para veterinários de equinos. São Paulo, Brasil.

Macpherson, M. L. 2011. Complications of the late pregnant mare. Proceedings of the European Veterinary Conference, 333-327.

Meyers, P. J., Bonnett, B. N. \& Mckee, S. L. 1991. Quantifying the occurrence of eary embryonic on three equine breeding farms. Canadian Veterinary Journal, 32, 655-672. 
Moreira, N., Kruger, E. R., Warth, J. F. G., Biesdorf, S, M., Goulart, M. M .M. \& Weiss, R. R. 1998. Aspectos etiológicos e epidemiológicos do aborto equino. Archives Veterinary Science, 3, 25-30.

Moreira, N., Weiss, R. R. \& Kruger, E. R. 2000. Frequência de anticorpos neutralizantes contra o hespesvirus equino tipo 1, Scientia Agraria, 1,9-14.

Newcobe, J. R. \& Wilson, M.C. 2005. Age, body weight, and pregnancy loss. Journal Equine Veterinary Science, 25, 188-94.

Nilsson, M. R. \& Corrêa, W. A. 1966. Isolamento do virus do aborto equino no Estado de São Paulo. Arquivos do Instituto Biológico, 33, 2325.

Ostlund, E. N. \& Powell, D.,1991. Bryans, G.T. Equine herpesvirus-1: a review. Proceedings of the thirty-sixth annual convention of the American Association of Equine Practitioners, Lexington, 387-395, 1991.

Palmer, E. \& Driacount, M. A. 1980. Use of ultrasonic echography in equine gynecology. Theriogenology, 13, 203-216.

Pereira, C. M., Adrien, M. L., Ladeira, S. R. L., Soares, N. P., Assis-Brasil, N. D. \& Schildi, A. L. 2012. Abortos em equinos na região Sul do Rio Grande do Sul: estudo de 72 casos. Pesquisa Veterinária Brasileira, 32, 22-26.

Peres, J. A., Zulpo, D. L., Lopes, B., Filadepho, A. L. \& Gueretz, J. S. 2008. Placentite fúngica em equino: relato de caso. Ambiência-Revista do Setor de Ciências Agrárias e Ambientais,4, 301-305.

Pescador, C. A., Corbellini, L. G., Loretti, A. P., Wunder Junior, E., Frantz, F. J. \& Driemeier, D. 2004. Aborto equino por Leptospira sp. Ciência Rural, 34, 271-274.

Pinto, C. R. F. 2011. Progestagens and progesterone. In: McKinnon, A.O; Suires, E. L.; Vaala, W. E. \& Varner, D.D. Equine Reproduction, Wiley-Blackwell, Iowa.

Prestes, N. C. \& Alvarenga F. C. L. 2006. Obstetrícia veterinária. Guanabara, Rio de Janeiro, Brasil.

Pycock, J. 2008. Problems in late pregnancy. Proceedings of the $10^{\text {th }}$ International Congress of World Equine Veterinary Association, Moscow, Russia, 241-243.
Rabelo, M. C., Taveiros, A. W., Melo, P. R. M., Chaves, R. M., Santos Júnior, E. R., Aguiar Filho, C. R., Bezerra, F. Q. G., Almeida Irmão, J. M., Freitas Neto, L. M., Lima, P. F. \& Oliveira, M. A. L. 2009. Taxas de prenhez e de perda embrionária em éguas da raça Mangalarga Machador em diferentes status reprodutivos utilizadas como receptoras em programas de transferência de embriões. Medicina Veterinária, 3, 13-19.

Reiner, U. R., Yunes, C. M. \& Reiner, C. 1998. Cio do Potro. In: VII Congresso Brasileiro deReprodução animal, 7,1988, Campinas, SP, Anais... Campinas, SP, Brasil.

Rodgerson, D. H. 2011. Prepubic and abdominal wall rupture. In: McKinnon, A. O., Squires, E. L., Vaala, W.E. \& Varner, D.D. Equine Reproduction, Wiley-Blackwell, Iowa.

Smith, K. C., Blunden, A. S., Whitwell, K. E., Dunn, K. A. \& Wales, A. D. 2003. Survey of equine abortion, stillbirth and neonatal death in the UK from 1988 to 1997. Equine Veterinary Journal, 35, 96-501.

Souza, F. A. A., Toledo, L. R. A. \& Lima, C.G. 2001. Ocorrência de perda embrionária precoce em equinos da raça Mangalarga acasaladas por monta natural ou submetidas a inseminação artificial. Ars Veterinária, 17, 183-189.

Souza, M. C. C. 1996. Prevalência da infecção pelo vírus da artrite dos equinos em cavalos criados no estado de São Paulo. Dissertação de mestrado FZEA-USP, Pirassununga, Brasil.

Squires, E. L., Mckinnon, A. O. \& Shideler, R. K. 1988. Use of ultrasonography in reproductive management of mares. Theriogenology, 29, 55-57.

Stanton, M. B., Steiner, J. V. \& Pugh, P.G. 2004. Endometrial cysts in the mare. Journal of Equine Veterinary Science, 24, 14-19.

Stout, T. A. E \& Allen, W. R. 2001. Role of prostaglandins in intrauterine migration of the equine conceptus. Journal of Reproduction and Fertility, 121, 771-775.

Studdert, M. J. \& Blackney, M. H. 1979. Equine herpesviruses: on the differentiation of respiratory from fetal strains of type 1 . Australian Veterinary Journal, 5, 488-492. 
Swerczek, T. W. 1991. Noninfections causes of abortion in the mare. Equine Practice Veterinary Medicine. 86, 1025-1029.

Tannus, R. J. \& Thun, R. 1995. Influence of endometrial cysts on conception rate of mares. Journal of Veterinary Medicine. 42, 275$283,1995$.

Taveiros, A. W., Oliveira, M. A. L., Lima, P. F., Tenório Filho, F., Bartolomeu, C. C., Santos, M. H. B., Oliveira, L.R.S., Iunes-Souza, T. C. \& Freitas, J. C. C. 2003. Ultrasonographic monitoaring of 103 recipient mares of diferente reproductive status during the first 30 days after embryo transfers. Veterinary Record, $153,558-560$.

Taveiros, A. W., Melo, P. R. M., Machado, P. P., Freitas Neto, L. M., Santos Junior, E. R. Santos, M. H. B., Lima, P. F. \& Oliveira, M. A. L. 2008. Perda de concepto em programa de inseminação artificial e de transferência de embriões em equino da raça Mangalarga Marchador. Medicina Veterinária, 2, 28-33.

Troedsson, M. H. T. \& Macperson, M. L. 2011. Placentitis. In: McKinnon, A. O, Squires, E. L., Vaala, W. E. \& Varner, D.D. Equine Reproduction. Wiley-Blackwell, Iowa.

Van Niekerk, C. M. \& Morgenthal, J. C. 1982. Fetal loss and the effect on stress on plasma progestagen levels in pregnant thoroughbred mares. Journal of Reproduction and Fertility. Supplement, 32, 453-457.

Vanderwall, D. K.2008. Early embryonic loss in the mare. Journal of equine veterinary, 28, 691701

Vasconcellos, S. A. 2000. Leptospirose em animais domésticos e silvestres - prevenção e controle. Oficina Estado da Arte e Prioridades para P \& D em Leptospirose/FIOCRUZ. Salvador, Brasil.

Villahoz, M. D. 1985. Some observations on early embryonic death in the mare, Journal Reproduction and ferlity, 32, 431-439.

Waelchli, R. O. 2011. Hydrops. In McKinnon, A.O; Squires, E.L., Vaala, W. E. \& Varner,
D.D. Equine Reproduction, Wiley-Blackwell, Iowa.

Watson, D. 2000. Post-breeding endometritis in the mare. Animal Reproduction Science, 60,221-232.

Weiblen, R. A., Raboske, M., Rebelato, M. C. \& Nobre, V.M. 1994. Abortions due to equine herpesvirus in southern Brazil. Brazilian Journal of Medical Biology Research, 27, 1317-320.

Whitwell, K. E. 2011. Abortions and stillbirths: A Pathologists Overview. In McKinnon, A. O, Squires, E. L., Vaala, W. E. \& Varner, D.D. Equine Reproduction, Wiley-Blackwell, Iowa.

Wilson, D. W. 1997. Equine herpervirus 1 myeloencephalopathy. Veterinary Clinics of North America: Equine Pratice, 20, 53-72.

Woods, G. L. 1987. Early pregnancy loss in brood mares. Journal of Reproduction and Fertility, (Suplement), 35, 455-459

Woods, G. L., Bilinski, J., Hillman, R. B., Mank, E. C. \& Sluijter, F. 1984. A fiel study on early pregnancy loss in standard bred and Thoroughbred mares. Equine Veterinary Science, 5, 254-267.

Woods, J., Bergfelt, D. R. \& Ginther, O.J. 1990. Effects of time of insemination relative to ovulation on pregnancy rate and embryonicloss rate in mares. Equine Veterinary Journal, $22,410-415$.

Woodward, E. \& Troedsson, M. H. 2012. Equine Breeding-Induced Endometritis: A review. Journal of Equine Veterinary Science, 33, 673682.

\section{Article History}

Received 17 September 2016

Accepted 07 October 2016

Available on line 20 October 2016

License information: This is an open-access article distributed under the terms of the Creative Commons Attribution License 4.0, which permits unrestricted use, distribution, and reproduction in any medium, provided the original work is properly cite 